\title{
Pulmonary Metastasectomy of Sarcoma: Is the Ratio of Surgical Margin to Nodule Size a Prognostic Factor?
}

\author{
Ali Özdil ${ }^{1} \quad$ Ahmet Kayahan Tekneci ${ }^{1} \quad$ Zafer Dökümcü $^{2} \quad$ Emre Divarcl $^{2} \quad$ Burçin Keçeci $^{3} \quad$ Murat Sezak $^{4}$ \\ Alpaslan Çakan ${ }^{1}$ Ufuk Çağırıcı ${ }^{1}$
}

${ }^{1}$ Department of Thoracic Surgery, Ege University School of Medicine, Ege University, İzmir, Turkey

2 Department of Pediatric Surgery, Ege University School of Medicine, Ege University, İzmir, Turkey

${ }^{3}$ Department of Orthopaedics and Traumatology, Ege University

School of Medicine, Ege University, İzmir, Turkey

${ }^{4}$ Department of Pathology, Ege University School of Medicine, Ege

University, İzmir, Turkey

Thorac Cardiovasc Surg 2019;67:675-682.
Address for correspondence Ali Özdil, MD, Department of Thoracic Surgery, Ege University School of Medicine, İzmir 35050, Turkey (e-mail: ali.ozdil@ege.edu.tr).

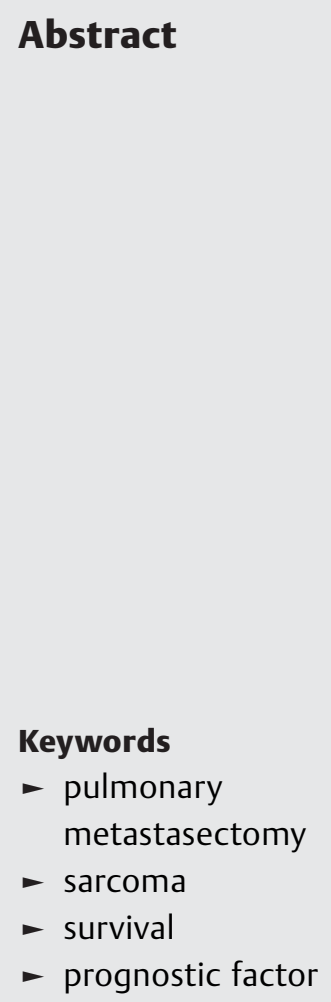

Background Main prognostic factors of improved survival after pulmonary metastasectomy (PM) for osteogenic and soft tissue sarcomas are suggested as histological type, number and size of pulmonary nodules, and disease-free interval (DFI).

Methods Sixty-nine patients who underwent PM between January 1999 and December 2017 were evaluated retrospectively. Relations between parameters and prognostic risk factors for overall survival (OS) and disease-free survival (DFS) were evaluated.

Results Osteosarcoma was the most common histologic type (36.2\%) and 21 of 25 cases were seen under the age 20 years $(p<0.001)$. Comparison of patient groups including osteosarcoma and nonosteosarcoma patients showed significant difference according to age $(p<0.001)$, nodule size $(p=0.033)$, ratio of surgical margin to nodule size $(p=0.007)$, and DFI $(p=0.039)$. Univariate analysis showed that the number of nodules $(p=0.008)$, ratio of surgical margin to nodule size $(p=0.001)$, and localization of nodule $(p=0.039)$ were significant factors associated with DFS. Also, nodule size ( $p=0.042)$, number of nodules $(p=0.003)$, ratio of surgical margin to nodule size $(p<0.001)$, and laterality $(p=0.027)$ were significant prognostic factors associated with OS. Cut-off values of ratio of surgical margin to nodule size for DFS and OS were calculated as 0.94 . Logistic regression analysis determined the ratio of surgical margin to nodule size as the common significant risk factor for DFS and OS.

Conclusions Our study showed that the ratio of surgical margin to nodule size $\geq 1$ should be taken as a common risk factor for DFS and OS. Therefore, resection of nodules with the possible widest surgical margin is an important point of PM.

\section{Introduction}

Sarcomas comprise $1 \%$ of adult malignancies and the lungs are the most common site of metastasis. The incidence of isolated pulmonary metastases is approximately $20 \%$ in sarcoma patients. ${ }^{1}$ Pulmonary metastases cannot be treated sufficiently by chemo- or radiotherapy due to their drug-resistant characteristics. Therefore, pulmonary metastasectomy (PM) is widely accepted as standard therapy in isolated pulmonary metastases and is associated with long-term survival. ${ }^{2,3}$ This received

July 10,2018

accepted after revision

August 13, 2018

published online

September 28, 2018 (c) 2019 Georg Thieme Verlag KG Stuttgart · New York
DOI https://doi.org/ 10.1055/s-0038-1670688. ISSN 0171-6425. 
survival rate is superior to that obtained with chemotherapy which is induced when PM is not proper. ${ }^{4}$

Although the outcomes and benefits of PM have been evaluated by several retrospective studies, the effectiveness of this treatment has not been disclosed because of the heterogeneity of the sarcomas. ${ }^{2}$ Prognostic factors associated with improved survival after PM are suggested as the histological type of primary tumor, the number and size of pulmonary nodules, disease-free interval (DFI), tumor doubling time, and age of patient. ${ }^{1-3}$ The 5 -year survival rate varying between 15 and $52 \%$ and recurrence rate of approximately $40 \%$ after PM were reported in the literature. ${ }^{5-7}$

In this study, we aimed to analyze clinical properties of patients who underwent PM for osteogenic and soft tissue sarcomas (STSs) and to investigate the prognostic factors associated with overall survival (OS) and disease-free survival (DFS) after PM.

\section{Materials and Methods}

Data of 69 patients who underwent PM for osteogenic and STS metastases between January 1999 and December 2017 were evaluated retrospectively, according to patients characteristics as age and gender, primary tumor characteristics as histological type, presentation age, localization and local recurrence, and pulmonary metastases characteristics as presentation time after sarcoma diagnosis, number, size, localization, laterality, and recurrence.

The primary tumor was histopathologically diagnosed first and curative surgical resection was performed after neoadjuvant chemotherapy in all patients by the orthopedic team. Complete local control of primary tumor and isolated pulmonary metastases were validated by radiological findings on computed tomography (CT) and/or positron emission tomography/CT (PET/CT) scan before PM. PET/CT scan was started to be used after the year 2004 in our center, so all 62 patients who were operated after 2004 had a PET/CT scan before the operation. There were no lymph node metastases detected in these patients by PET/CT scan before the operation. PM was performed with the aim of complete radical resection of metastases. Mediastinal or hilar lymph node dissection or sampling was not performed routinely for this study population with sarcomas.

Video-assisted thoracic surgery (VATS) was used in patients having less than three ipsilateral metastasis detected by a highly sensitive multislice CT scan if available for VATS preoperatively or perioperatively. Other patients were operated by thoracotomy.

A anthracycline-based neoadjuvant chemotherapy was applied to adult patients with osteosarcoma for 3 or 4 cycles and T-10 protocol (Methotrexate, Adriamycin, Cyclophosphamide, Cis-Platin, Actinomycin-D, Bleomycin) was used as adjuvant chemotherapy for 8 cycles to 1 year depending to the response of the neoadjuvant chemotherapy. For Ewing's sarcoma and other STS, VAC/IE protocol (Vincristine, Adriamycin, Cyclophosphamide/Ifosfamide, Etoposide) and/or radiotherapy was used as neoadjuvant and adjuvant chemotherapy for 4 cycles preoperatively and 8 cycles to 1 year depending on the response.
In early years, Mayo Pilot II protocol (Methotrexate, CisPlatin, Doxorubicin, Ifosfamide) and in recent years EURAMOS protocol (Methotrexate, Cis-Platin, Doxorubicin, Ifosfamide, Etoposide) were applied as neoadjuvant chemotherapy for 3 or 4 cycles to pediatric patients with osteosarcoma and highdose methotrexate was used as adjuvant chemotherapy for 6 to 12 months depending to the response. For Ewing's sarcoma, EICESS-92 protocol (Vincristine, Doxorubicin, Ifosfamide, Dactinomycin) was used as neoadjuvant chemotherapy for 4 cycles and no adjuvant chemotherapy was applied. The administration of chemotherapy and long-term follow-up of the patients was done by medical and pediatric oncology departments.

Patients were divided into two groups according to the diagnosis as "osteosarcoma group" and "nonosteosarcoma group." These two groups were compared in terms of age, primary sarcoma localization, DFI, diameter, volume, number, localization and laterality of nodules, ratio of surgical margin to nodule size, and operation type for the first PM.

The largest nodule was taken as reference for the determination of size and ratio of surgical margin to nodule size. Surgical margin was calculated as the distance from the staple line to the edge of the nodule. Histopathological findings were used for the determination of these parameters.

The OS was calculated from the time of first PM to the time of death or last follow-up, and DFS was measured from the time of first PM to the recurrence of pulmonary metastases or death. DFI was defined as the time between the first diagnosis of the primary tumor and the first PM. The relation between the prognostic risk factors and OS and DFS were evaluated.

Analyses were conducted via IBM SPSS Statistics 23. Kolmogorov-Smirnov test was used for assessment of data distribution. Continuous variables were summarized as mean \pm standard deviation. Categorical data were shown as percentages and compared using the Fisher's exact test for 2 groups and the Pearson's chi-squared test for $>2$ groups. Student's $t$ test and Mann-Whitney $U$-test were performed for data with normal and abnormal distribution, respectively.

OS and DFS, the effects of the factors on mortality, were examined using the Kaplan-Meier and Mantel-Cox (log rank) analysis. Cox regression analysis was performed to determine the effects of factors on DFS and OS. The cut-off values for the ratio of surgical margin to nodule size were calculated using receiver operating characteristic curve analysis and logistic regression models were performed for significance. Statistical level of significance was taken as $p$-value of $<0.05$ for all tests.

The study was approved by the institutional ethics review panel. Patient consent for data collection was not required.

\section{Results}

Mean age of patients (43 males, 26 females) was $25.32 \pm 14.30$ years (range, 2-70 years) at the time of primary tumor diagnosis and $30.13 \pm 14.00$ years at the time of first PM (range, 11-75 years). Osteosarcoma was the most common histologic type (36.2\%) followed by Ewing's sarcoma (24.6\%) and synovial sarcoma (18.8\%). Primary site of the sarcoma was lower extremity in 47 (68.1\%) followed by upper extremity in $15(21.7 \%)$ patients. A total of 
102 operations were performed. Pulmonary wedge resection via thoracotomy $(44.12 \%)$ was the most common type of operation followed by video thoracoscopy (41.18\%).

In the analysis of first PM, number of nodules resected in a session ranged between 1 (48 patients, 69.60\%) and 9 (1 patient, 1.4\%). Mean size of the largest nodules detected was $23.61 \pm 22.61 \mathrm{~mm}$ (range, $2-140 \mathrm{~mm}$ ). Nodules were bilateral in $12(17.6 \%)$ patients. Segmentectomy or lobectomy was the largest anatomic resection type for the first PM with a rate of $7.24 \%$ ( 5 patients). The surgical approach was thoracotomy in 38 (55.1\%) and VATS in 31 (44.9\%) patients. Complete resection could not be achieved in 4 (5.8\%) patients due to the enlargement of tumor. The mean of the DFI was $28.32 \pm 29.78$ months (range, 5-134 months) (- Table 1). All patients received chemotherapy after the PM.

Table 1 Patient characteristics

\begin{tabular}{|c|c|}
\hline & $n(\%)$ \\
\hline Gender (male/female) & $43(62.3) / 26(37.7)$ \\
\hline $\begin{array}{l}\text { Age at first PM } \\
\text { (mean } \pm S D, \\
\text { range) }(y)\end{array}$ & $30.13 \pm 14.00(11-75)$ \\
\hline \multicolumn{2}{|l|}{ Histology } \\
\hline Osteosarcoma & $25(36.2)$ \\
\hline Ewing's sarcoma & $17(24.6)$ \\
\hline Synovial sarcoma & $13(18.8)$ \\
\hline Others & $14(20.4)$ \\
\hline \multicolumn{2}{|l|}{ Primary site } \\
\hline Lower extremity & $47(68.1)$ \\
\hline Upper extremity & $15(21.7)$ \\
\hline Vertebrae & $5(7.2)$ \\
\hline Chest wall & $2(2.9)$ \\
\hline $\begin{array}{l}\text { No of nodules } \\
(1 / 2 / 3 / 4 / 5 / 6 / 8 / 9)\end{array}$ & $\begin{array}{l}48(69.6) / 8(11.6) / 6(8.7) / 2(2.9) / \\
2(2.9) / 1(1.4) / 1(1.4) / 1(1.4)\end{array}$ \\
\hline $\begin{array}{l}\text { Size of nodule } \\
\text { (mean } \pm \mathrm{SD} \text {, } \\
\text { range) }(\mathrm{mm})\end{array}$ & $23.61 \pm 22.61(2-140)$ \\
\hline $\begin{array}{l}\text { Surgical margin/ } \\
\text { nodule size } \\
(\text { mean } \pm S D)\end{array}$ & $0.75 \pm 0.69$ \\
\hline $\begin{array}{l}\text { Laterality } \\
\text { (unilateral/bilateral) }\end{array}$ & 57 (82.6\%)/12 (17.4\%) \\
\hline \multicolumn{2}{|l|}{ Surgical procedure } \\
\hline $\begin{array}{l}\text { Pulmonary wedge } \\
\text { resection }\end{array}$ & $62(89.8)$ \\
\hline $\begin{array}{l}\text { Segment/lobe/ } \\
\text { pneumonectomy }\end{array}$ & $7(10.2)$ \\
\hline Complete resection & $65(94.2)$ \\
\hline $\begin{array}{l}\text { DFI (mean } \pm S D \text {, } \\
\text { range) }(\mathrm{mo})\end{array}$ & $39.13 \pm 36.32(4-221)$ \\
\hline Recurrence & $38(55.1)$ \\
\hline
\end{tabular}

Abbreviations: DFI, disease-free interval; PM, pulmonary metastasectomy; SD, standard deviation.
Under the age of 20 years, osteosarcoma was the most common histologic type and 21 of 25 cases were seen in this age group $(p<0.001)$. All of the osteosarcoma cases were younger than 40 years of age $(p<0.001)$. In spite of these, nearly all of the others group (13 of 14 cases) including malign fibrous histiocytoma, liposarcoma, chondrosarcoma, and pleomorphic cell sarcoma was observed over the age of 20 years $(p<0.001)$. Also, osteosarcoma was the histologic type that had been resected with the highest ratio of surgical margin to nodule size $(p=0.018)$. There was no significant relation between histologic type and DFI.

The comparison of groups showed significant difference according to age ( $p<0.001$ and $p=0.002)$, size of nodule $(p=0.033)$, ratio of surgical margin to nodule size $(p=0.007)$, and DFI $(p=0.039)$. There was no significant difference according to gender, site of primary sarcoma, volume, number, localization and laterality of nodule, recurrence, and operation type for the first PM (-Table 2 ).

The median follow-up time after the first PM was 35 months (range, 2-194 months). The estimated 5-year survival was $48 \%$ with a median of 43 months and 5-year DFS was $38 \%$ with a median of 22 months (-Fig. 1 ).

The cut-off values of ratio of surgical margin to nodule size for DFS and OS were calculated as 0.94 for both with odds ratios of 4.727 and 6.587, respectively. The ratio was grouped as $\geq 1$ and $<1$ according to this cut-off value.

The univariate analysis showed that the number of nodules $(p=0.008)$, ratio of surgical margin to nodule size $(p=0.001)$, and localization of the nodule $(p=0.039)$ were the significant factors associated with DFS (-Fig. 2). Also, nodule size $(p=0.042)$, number of nodules $(p=0.003)$, ratio of surgical margin to nodule size $(p<0.001)$, and laterality $(p=0.027)$ were significant prognostic factors associated with OS (-Fig. 3) (-Table 3 ). The multivariate analyses demonstrated that the ratio of surgical margin to nodule size was an independent prognostic factor for DFS (-Table 4), while the number of nodules and ratio of surgical margin to nodule size were both independent prognostic factors for OS ( - Table 5). Also, the logistic regression analysis determined the ratio of surgical to nodule size as the common significant risk factor for DFS and OS (-Table 6).

\section{Discussion}

Especially, pulmonary metastasis is a poor prognostic factor for STS, but the survival can be extended with PM in selected patients. Therefore, PM remains a cornerstone in the treatment of STS since neither chemotherapy nor radiotherapy has shown any effective results. ${ }^{8,9}$

In this study, overall 5-year survival was $48 \%$ with a median of 43 months. This was a similar and favorable survival outcome when compared with the recent studies. ${ }^{2,3,6}$ Beside, the 5-year DFS (43\% with a median of 40 months) was significantly higher in our highly selected patient group when compared with the same studies. This can be a result of 
Table 2 Comparison of osteosarcoma and nonosteosarcoma patients according to prognostic factors

\begin{tabular}{|c|c|c|c|}
\hline & Osteosarcoma & Nonosteosarcoma & $p$ \\
\hline \multicolumn{4}{|l|}{ Age } \\
\hline$<20$ & $21(30.4 \%)$ & $16(23.2 \%)$ & \multirow[t]{2}{*}{$<0.001$} \\
\hline$\geq 20$ & $4(5.8 \%)$ & $28(40.6 \%)$ & \\
\hline$<40$ & $25(36.2 \%)$ & $30(43.5 \%)$ & \multirow[t]{2}{*}{0.002} \\
\hline$\geq 40$ & 0 & $14(20.3 \%)$ & \\
\hline \multicolumn{4}{|l|}{ Gender } \\
\hline Male & $15(21.7 \%)$ & $28(40.6 \%)$ & \multirow[t]{2}{*}{0.764} \\
\hline Female & $10(14.5 \%)$ & $16(23.2 \%)$ & \\
\hline \multicolumn{4}{|c|}{ Site of primary sarcoma } \\
\hline Lower extremity & $18(26.1 \%)$ & $29(42.0 \%)$ & \multirow[t]{4}{*}{0.727} \\
\hline Upper extremity & $5(7.2 \%)$ & $10(14.5 \%)$ & \\
\hline Vertebrae & $2(2.9 \%)$ & $3(4.3 \%)$ & \\
\hline Chest wall & 0 & $2(2.9 \%)$ & \\
\hline \multicolumn{4}{|l|}{ Size of nodule $(\mathrm{mm})$} \\
\hline$<20$ & $18(26.1 \%)$ & $20(29.0 \%)$ & \multirow[t]{2}{*}{0.033} \\
\hline$\geq 20$ & $7(10.1 \%)$ & $24(34.8 \%)$ & \\
\hline \multicolumn{4}{|l|}{ No. of nodule } \\
\hline$\leq 2$ & $20(29.0 \%)$ & $36(52.2 \%)$ & \multirow[t]{2}{*}{0.853} \\
\hline$>2$ & $5(7.2 \%)$ & $8(11.6 \%)$ & \\
\hline \multicolumn{4}{|c|}{ Surgical margin/size of nodule } \\
\hline$<1$ & $12(\% 17.4)$ & $35(50.7 \%)$ & \multirow[t]{2}{*}{0.007} \\
\hline$\geq 1$ & $13(18.8 \%)$ & $9(13 \%)$ & \\
\hline \multicolumn{4}{|l|}{ Laterality } \\
\hline Unilateral & $20(29.0 \%)$ & 37 (53.6\%) & \multirow[t]{2}{*}{0.667} \\
\hline Bilateral & $5(7.2 \%)$ & $7(10.1 \%)$ & \\
\hline \multicolumn{4}{|l|}{ Operation type } \\
\hline Thoracotomy & $16(23.2 \%)$ & $22(31.9 \%)$ & \multirow[t]{2}{*}{0.261} \\
\hline VATS & $9(13.0 \%)$ & $22(31.9 \%)$ & \\
\hline \multicolumn{4}{|l|}{ DFI } \\
\hline$<12 \mathrm{mo}$ & $4(5.8 \%)$ & $1(1.4 \%)$ & \multirow[t]{4}{*}{0.039} \\
\hline$\geq 12$ to $<24 \mathrm{mo}$ & $8(11.6 \%)$ & $13(18.8 \%)$ & \\
\hline$\geq 24$ to $<36 \mathrm{mo}$ & $9(13.0 \%)$ & $11(15.9 \%)$ & \\
\hline$\geq 36 \mathrm{mo}$ & $4(5.8 \%)$ & $19(27.5 \%)$ & \\
\hline \multicolumn{4}{|l|}{ Recurrence } \\
\hline Yes & $13(18.8 \%)$ & 25 (36.2\%) & \multirow[t]{2}{*}{0.699} \\
\hline No & 12 (17.4\%) & 19 (27.5\%) & \\
\hline
\end{tabular}

Abbreviations: DFI, disease-free interval; VATS, video-assisted thoracic surgery.

patient selection which affects the risk factors of survival like histologic type, tumor grade and aggressiveness, number of metastasis, localization, and laterality. Also, all of the patients in this study received chemotherapy before and after the resection of the primary tumor and after PM. The approach type with a VATS rate of $45 \%$ was another mark of patient selection.
Histologic type was considered as a prognostic factor in some recent studies, ${ }^{1,10,11}$ but we did not find any difference in comparing the most frequent histologic types. We grouped patients as osteosarcoma and nonosteosarcoma and compared these two groups according to patient characteristics. Osteosarcoma was seen especially before the age of 20 years and none of them was diagnosed after the age of 40 years. The 


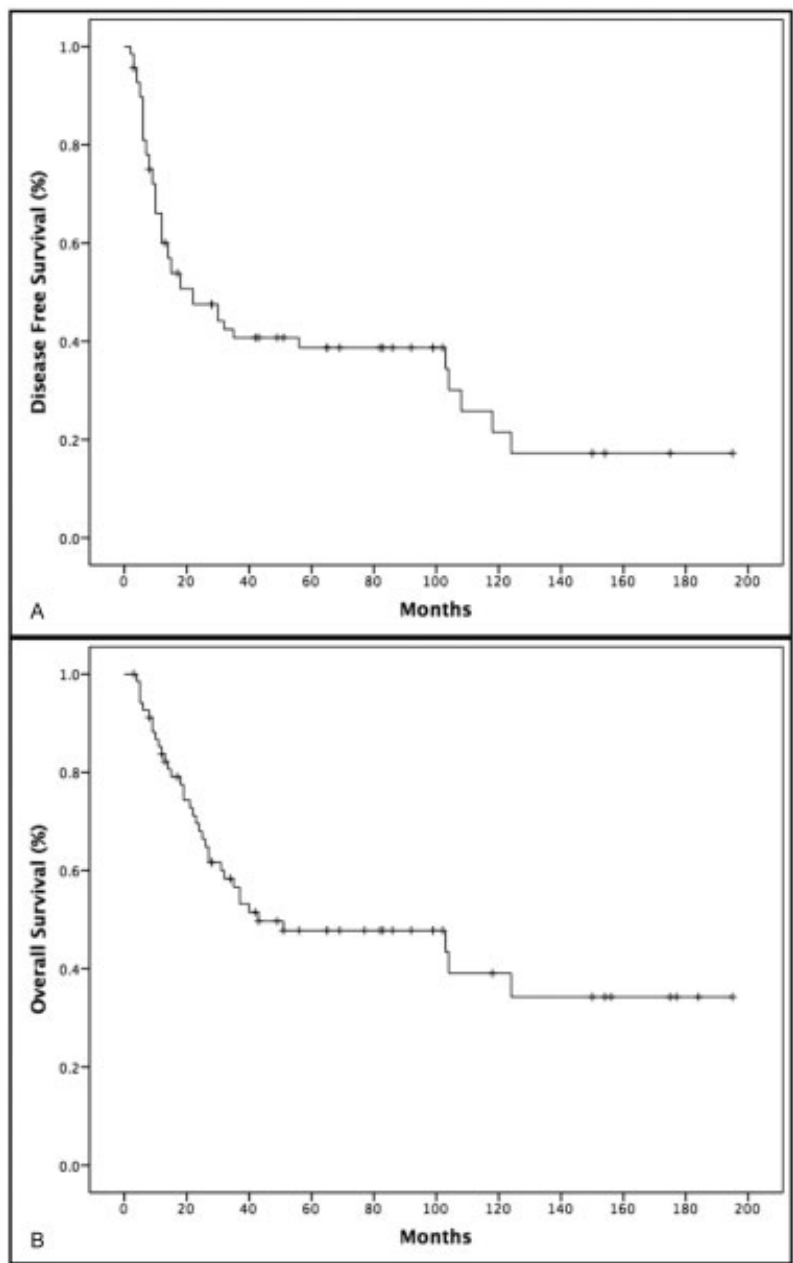

Fig. 1 Disease-free (A) and overall (B) survival of patients after pulmonary metastasectomy.

nodule size and ratio of the surgical margin to nodule size was significantly different in the osteosarcoma group. These differences may be due to the nature of the sarcoma and a closer follow-up of pediatric patients for metastatic diseases is mandated. Although we expected a difference because of these factors, there was no significant difference in terms of survival between the two groups. On the other hand, DFI was significantly shorter in the osteosarcoma group and we thought this as a reason of absence of difference.

Most of the recent studies in the literature mentioned DFI as a very important prognostic factor for the survival of sarcoma patients with pulmonary metastasis. Especially DFI longer than 12 months was indicated as a strong prognostic factor for DFS and OS. ${ }^{3,12,13}$ In our study, there was no correlation between DFI and survival, despite different grouping variations according to interval. This can be due to the number of patient included and distribution of histologic types in our series. Other studies similar to that of ours also reported similar findings, that is, no difference. ${ }^{14,15}$

Number of nodules, nodule size, laterality, and complete resection were reported as the main risk factors in previously published studies involving large number of patients. $3,7,8,12,13$

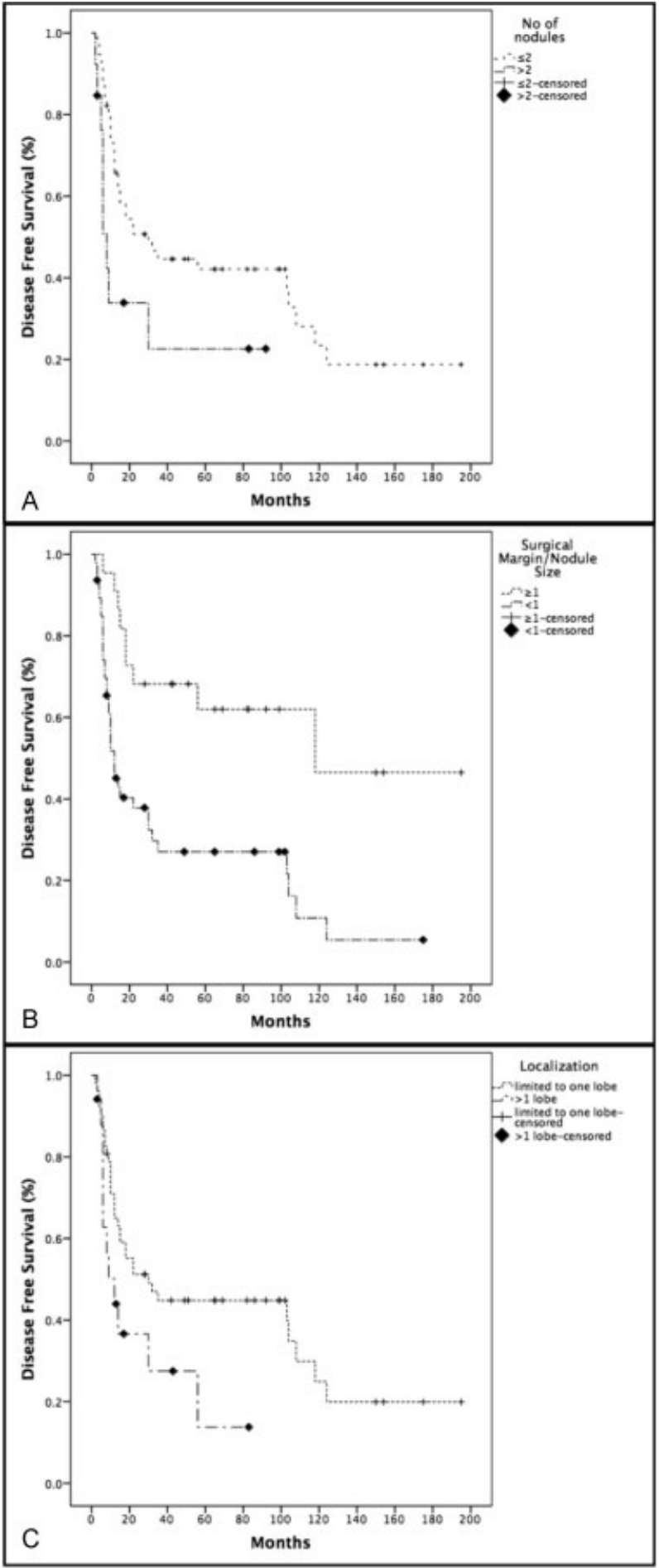

Fig. 2 Significant risk factors for disease-free survival: (A) number of nodules, (B) ratio of surgical margin to nodule size, and (C) localization of nodule.

Number of nodules, ratio of surgical margin to nodule size, and localization for DFS, nodule size, nodule volume, number of nodules, ratio of surgical margin to nodule size, and laterality for OS were the significant risk factors in univariate analysis. The common risk factors for DFS and OS were number of nodules and ratio of surgical margin to nodule size. After the multivariate analysis, the ratio was the common significant 

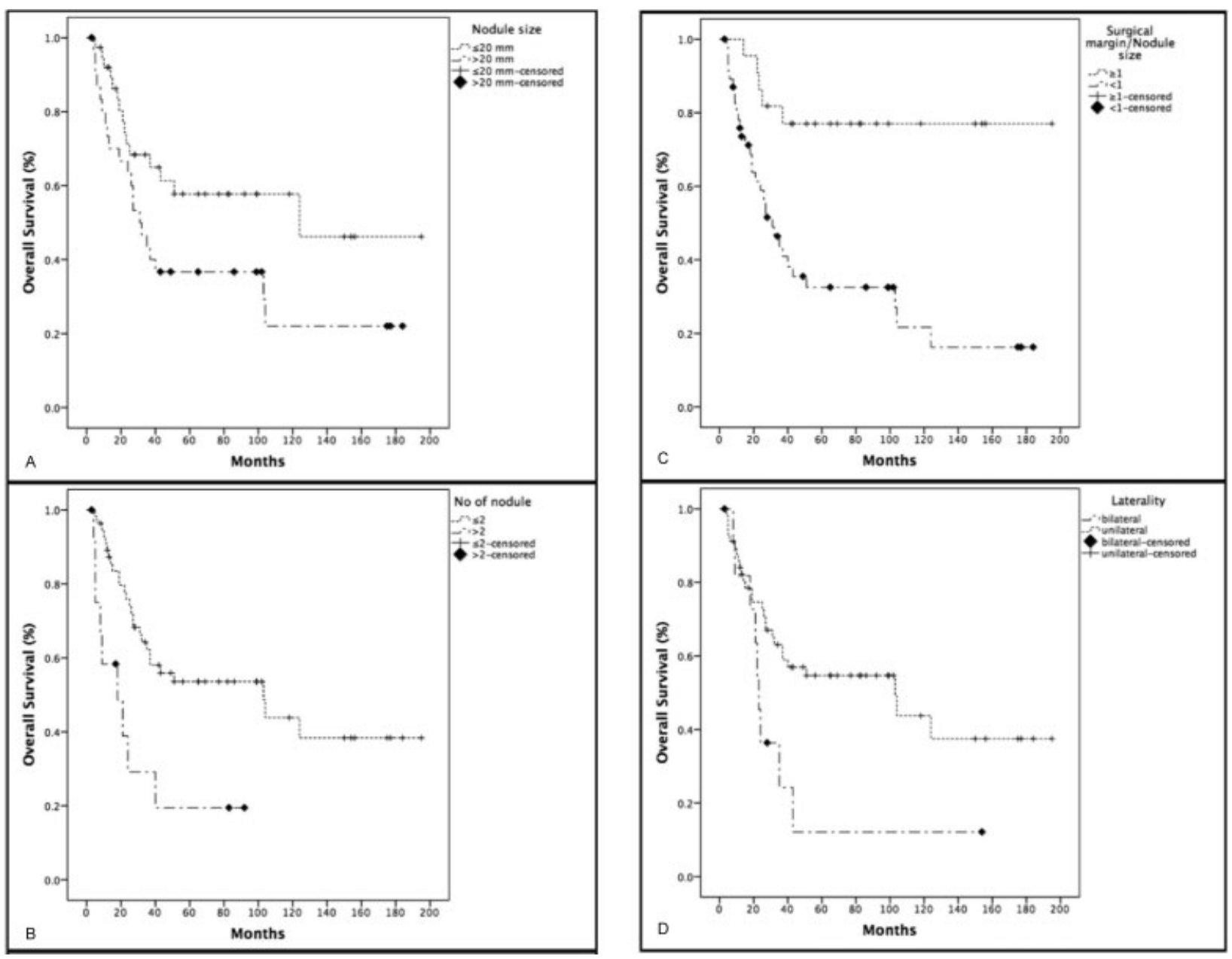

Fig. 3 Significant risk factors for overall survival: (A) nodule size, (B) number of nodules, (C) ratio of surgical margin to nodule size, and (D) laterality.

risk factor with $p$-values of 0.001 and 0.006 for DFS and OS, respectively. The cut-off values were determined as 0.94 for this factor and showed that the patients could be grouped as $<1$ and $\geq 1$ according to the ratio. This ratio was also considered as a significant prognostic factor by the results of logistic regression analysis. We did not evaluate the effect of complete resection because of the results already known. Instead, we examined the ratio of surgical margin to nodule size which was thought as more meaningful. This analysis showed the importance of length of tumor-free surgical margin for recurrence and survival.

Hilar and mediastinal lymph node involvement is very rare especially in sarcomas, so the role of lymph node dissection in sarcoma patients remain contradictory. ${ }^{16,17}$ Because of this contradiction, some centers perform no lymph node sampling or dissection whereas others favor lymph node sampling or radical dissection. ${ }^{18}$ We do not perform lymph node sampling or dissection routinely especially in patients with negative CT and PET/CT scan, that is, if there is no significant finding of lymph node involvement perioperatively.

Type of surgical approach is a common issue today. Number of nodules, localization, and laterality are main determinants in selecting the surgical approach. Two studies, one of them including only sarcoma patients ${ }^{19}$ and the other including colorectal cancer patients, ${ }^{20}$ applied VATS (with nodules less than 3 and peripheral localization, etc.) and yielded similar survival benefits. We also preferred VATS for the nodules which were few and peripheral and found no difference in DFS and OS. In addition, parenchymal protective surgery is an important point of PM, and therefore the surgeon must consider this when selecting the kind of approach.

\section{Limitations}

There are some limitations of this study that should be kept in view when commentating. This is a retrospective and single center-based study and hence the methodology used cannot be generalized to other centers. Also, because of the retrospective design and the missing data the grade of the primary sarcoma which has an effect on survival could not be analyzed.

\section{Comment}

PM seems to be the best choice in selected sarcoma patients with pulmonary metastasis. The efficacy of chemo-/radiotherapy on survival is limited according to PM. Size, number and localization of nodules, DFI, complete resection, and 
Table 3 Univariate analyzes of factors associated with DFS and OS

\begin{tabular}{|c|c|c|c|c|}
\hline & Mean (median) DFS & $p$ & Mean (median) OS & $p$ \\
\hline \multicolumn{5}{|l|}{ Gender } \\
\hline Male & $71.9(32)$ & \multirow[t]{2}{*}{0.189} & $77.1(32)$ & \multirow[t]{2}{*}{0.101} \\
\hline Female & $90.4(77)$ & & $112.5(103)$ & \\
\hline \multicolumn{5}{|l|}{ Age } \\
\hline$\leq 20$ & $89.1(37)$ & \multirow[t]{2}{*}{0.388} & $105.2(104)$ & \multirow[t]{2}{*}{0.457} \\
\hline$>20$ & $64.7(40)$ & & $71.9(43)$ & \\
\hline \multicolumn{5}{|l|}{ Histology } \\
\hline Osteosarcoma & $95.5(51)$ & \multirow[t]{2}{*}{0.205} & 110.2() & \multirow[t]{2}{*}{0.262} \\
\hline Nonosteosarcoma & $66.9(40)$ & & $75.5(40)$ & \\
\hline \multicolumn{5}{|l|}{ DFI } \\
\hline$\leq 24 \mathrm{mo}$ & $82.1(27)$ & \multirow[t]{2}{*}{0.539} & $86.8(27)$ & \multirow[t]{2}{*}{0.470} \\
\hline$>24 \mathrm{mo}$ & $78.5(43)$ & & $92.7(51)$ & \\
\hline \multicolumn{5}{|l|}{ Nodule size } \\
\hline$\leq 20 \mathrm{~mm}$ & $87.7(56)$ & \multirow[t]{2}{*}{0.081} & $114.3(124)$ & \multirow[t]{2}{*}{0.022} \\
\hline$>20 \mathrm{~mm}$ & $67.3(31)$ & & $68(31)$ & \\
\hline \multicolumn{5}{|l|}{ No of nodule } \\
\hline$\leq 2$ & $86.4(56)$ & \multirow[t]{2}{*}{0.027} & $102.7(103)$ & \multirow[t]{2}{*}{0.003} \\
\hline$>2$ & $30.5(18)$ & & $30.5(18)$ & \\
\hline \multicolumn{5}{|c|}{ Surgical margin/nodule size } \\
\hline$<1$ & $56.5(27)$ & \multirow[t]{2}{*}{0.001} & $62.1(31)$ & \multirow[t]{2}{*}{$<0.001$} \\
\hline$\geq 1$ & $126.7(156)$ & & 155.8() & \\
\hline \multicolumn{5}{|l|}{ Nodule localization } \\
\hline Limited to one lobe & $87.5(51)$ & \multirow[t]{2}{*}{0.041} & $99.8(103)$ & \multirow[t]{2}{*}{0.088} \\
\hline$>1$ lobe & $51.9(24)$ & & $60.0(24)$ & \\
\hline \multicolumn{5}{|l|}{ Laterality } \\
\hline Unilateral & $85.5(56)$ & \multirow[t]{2}{*}{0.183} & $101.6(103)$ & \multirow[t]{2}{*}{0.027} \\
\hline Bilateral & $39.5(23)$ & & $39.5(23)$ & \\
\hline \multicolumn{5}{|l|}{ Operation type } \\
\hline Thoracotomy & $75.4(37)$ & \multirow[t]{2}{*}{0.561} & $87.4(37)$ & \multirow[t]{2}{*}{0.423} \\
\hline VATS & $75.3(56)$ & & $84.0(103)$ & \\
\hline
\end{tabular}

Abbreviations: DFI, disease-free interval; DFS, disease-free survival; OS, overall survival; VATS, video-assisted thoracic surgery.

Table 4 Multivariate analysis of the factors associated with DFS rates

\begin{tabular}{|l|l|l|l|}
\hline Variables & $\begin{array}{l}\text { Hazard } \\
\text { ratio }\end{array}$ & $95 \% \mathrm{Cl}$ & $p$ \\
\hline No of nodule & 0.617 & $0.222-1.713$ & 0.354 \\
\hline $\begin{array}{l}\text { Ratio of surgical } \\
\text { margin to nodule size }\end{array}$ & 3.349 & $1.595-7.034$ & 0.001 \\
\hline Nodule localization & 0.659 & $0.216-2.013$ & 0.464 \\
\hline
\end{tabular}

Abbreviations: $\mathrm{Cl}$, confidence interval; DFS, disease-free survival.
Table 5 Multivariate analysis of the factors associated with overall survival rates

\begin{tabular}{|l|l|l|l|}
\hline Variables & $\begin{array}{l}\text { Hazard } \\
\text { ratio }\end{array}$ & $95 \% \mathrm{Cl}$ & $p$ \\
\hline Nodule size & 0.939 & $0.431-2.046$ & 0.874 \\
\hline No of nodule & 0.395 & $0.165-0.945$ & 0.037 \\
\hline $\begin{array}{l}\text { Ratio of surgical } \\
\text { margin to nodule size }\end{array}$ & 4.531 & $1.534-13.384$ & 0.006 \\
\hline Laterality & 1.895 & $0.785-4.570$ & 0.155 \\
\hline
\end{tabular}

Abbreviation: $\mathrm{Cl}$, confidence interval. 
Table 6 Classification tables for ratio of survival margin to nodule size on the logistic regression model

\begin{tabular}{|l|l|l|l|l|}
\hline \multicolumn{2}{|l|}{} & Predicted & Recurrence & \\
\hline \multicolumn{2}{|l|}{ Observed } & $(-)$ & $(+)$ & $\begin{array}{l}\text { Percentage } \\
\text { correct }\end{array}$ \\
\hline \multirow{2}{*}{ Recurrence } & $(-)$ & 13 & 11 & 54.2 \\
\cline { 2 - 5 } & $(+)$ & 9 & 36 & 80.0 \\
\hline $\begin{array}{l}\text { Overall } \\
\text { percentage }\end{array}$ & & & 71.0 \\
\hline \multirow{2}{*}{\begin{tabular}{l} 
Mortality \\
\cline { 3 - 5 }
\end{tabular}} & Alive & 17 & 16 & \\
\cline { 2 - 5 } & Exitus & 5 & 31 & 86.1 \\
\hline $\begin{array}{l}\text { Overall } \\
\text { percentage }\end{array}$ & & & 69.6 \\
\hline
\end{tabular}

laterality are reported as the main risk factors of survival. Although this prognostic factor should be supported by randomized controlled studies with large patient numbers and meta-analysis, this study shows that the ratio of surgical margin to nodule size $\geq 1$ must be taken as a common risk factor for DFS and OS. Therefore, the resection of the nodules with the possible widest surgical margin is an important point of PM.

\section{Conflict of Interest}

None.

\section{References}

1 Blackmon SH, Shah N, Roth JA, et al. Resection of pulmonary and extrapulmonary sarcomatous metastases is associated with long-term survival. Ann Thorac Surg 2009;88(03):877-884, discussion 884-885

2 MizunoT, Taniguchi T, Ishikawa Y, et al. Pulmonary metastasectomy for osteogenic and soft tissue sarcoma: who really benefits from surgical treatment? Eur J Cardiothorac Surg 2013;43(04):795-799

3 Kim S, Ott HC, Wright CD, et al. Pulmonary resection of metastatic sarcoma: prognostic factors associated with improved outcomes. Ann Thorac Surg 2011;92(05):1780-1786, discussion 1786-1787

4 García Franco CE, Torre W, Tamura A, et al. Long-term results after resection for bone sarcoma pulmonary metastases. Eur J Cardiothorac Surg 2010;37(05):1205-1208

5 Pastorino U, Buyse M, Friedel G, et al; International Registry of Lung Metastases. Long-term results of lung metastasectomy: prognostic analyses based on 5206 cases. J Thorac Cardiovasc Surg 1997;113(01):37-49

6 Predina JD, Puc MM, Bergey MR, et al. Improved survival after pulmonary metastasectomy for soft tissue sarcoma. J Thorac Oncol 2011;6(05):913-919

7 Smith R, Pak Y, Kraybill W, Kane JM III. Factors associated with actual long-term survival following soft tissue sarcoma pulmonary metastasectomy. Eur J Surg Oncol 2009;35(04):356-361

8 Grimer R, Judson I, Peake D, Seddon B. Guidelines for the management of soft tissue sarcomas. Sarcoma 2010;2010:506182

9 ESMO / European Sarcoma Network Working Group. Soft tissue and visceral sarcomas: ESMO Clinical Practice Guidelines for diagnosis, treatment and follow-up. Ann Oncol 2012;23(Suppl 7):vii92-vii99

10 Kang S, Kim HS, Kim S, Kim W, Han I. Post-metastasis survival in extremity soft tissue sarcoma: a recursive partitioning analysis of prognostic factors. Eur J Cancer 2014;50(09):1649-1656

11 Casson AG, Putnam JB, Natarajan G, et al. Five-year survival after pulmonary metastasectomy for adult soft tissue sarcoma. Cancer 1992;69(03):662-668

12 Dossett LA, Toloza EM, Fontaine J, et al. Outcomes and clinical predictors of improved survival in a patients undergoing pulmonary metastasectomy for sarcoma. J Surg Oncol 2015;112(01): 103-106

13 Chudgar NP, Brennan MF, Munhoz RR, et al. Pulmonary metastasectomy with therapeutic intent for soft-tissue sarcoma. J Thorac Cardiovasc Surg 2017;154(01):319-330.e1

14 Okiror L, Peleki A, Moffat D, et al. Survival following pulmonary metastasectomy for sarcoma. Thorac Cardiovasc Surg 2016;64 (02):146-149

15 Pfannschmidt J, Klode J, Muley T, Dienemann H, Hoffmann H. Pulmonary metastasectomy in patients with soft tissue sarcomas: experiences in 50 patients. Thorac Cardiovasc Surg 2006;54(07): 489-492

16 Allen MS, Putnam JB. Secondary tumors of the lung. In: Shields TW, LoCicero J III, Reed CE, Feins RH, eds. General Thoracic Surgery. 7th ed. Philadelphia: Lippincott Williams \& Wilkins; 2009:1619-1646

17 Seebacher G, Decker S, Fischer JR, Held M, Schäfers HJ, Graeter TP. Unexpected lymph node disease in resections for pulmonary metastases. Ann Thorac Surg 2015;99(01):231-236

18 Internullo E, Cassivi SD, Van Raemdonck D, Friedel G, Treasure T; ESTS Pulmonary Metastasectomy Working Group. Pulmonary metastasectomy: a survey of current practice amongst members of the European Society of Thoracic Surgeons. J Thorac Oncol 2008;3(11):1257-1266

19 Gossot D, Radu C, Girard P, et al. Resection of pulmonary metastases from sarcoma: can some patients benefit from a less invasive approach? Ann Thorac Surg 2009;87(01):238-243

20 Nakajima J, Murakawa T, Fukami T, Takamoto S. Is thoracoscopic surgery justified to treat pulmonary metastasis from colorectal cancer? Interact Cardiovasc Thorac Surg 2008;7(02):212-216, discussion 216-217 